\title{
Impact of Educational Sessions for Epileptic Children Mothers on Their knowledge, Adherence to Antiepileptic Drugs and Seizures Severity among their Children
}

\author{
Fawzia El Sayed Abusaad ${ }^{1}$, Adel El-Wehedy ${ }^{2}$ \\ ${ }^{1}$ Assistant professor of pediatric nursing ,Mansoura University \\ ${ }^{2}$ Professor of Occupational medicine, Mansoura University
}

\begin{abstract}
:
Background: Epilepsy is a chronic medical condition, which requires long term management. Adherence to antiepileptic drugs (AEDs) is crucial for preventing the risk of recurrent seizures.

Aim of this study is to examine the impact of educational Sessions on maternal knowledge, adherence to antiepileptic drugs and seizure severity among their epileptic children.

Methods: A quasi experimental design (pre, post three month and follow up after six month) was conducted on 100 mothers with their epileptic children who willing to participate at inpatient unit and outpatient clinic of neurology department at Mansoura University Children's hospital. Three tools were used to collect the required data; structured interview questionnaire, medication adherence scale and seizure severity scale, then educational sessions was developed according to mothers needs.

Results: More than half of the studied mothers (59\%) have poor knowledge and only (3\%) of them have good knowledge. As regard adherence to antiepileptic drugs about three quarters of mothers (73\%) are nonadherent. Also seventy two (72\%) of children has moderate severity of epilepsy, (15\%) has sever level and only (13\%) has mild level of epilepsy severity before intervention, but after three and six month of intervention $57 \%$ \&44\% of mothers had good knowledge, the majority of them $95 \%$ \& $98 \%$ respectively become adherent to drugs administration and the severity level of seizure among children were decreased. Also (91\%) of mothers reported that forgetness is the major causes of non- adherence to antiepileptic drug administration.

Conclusion: An improvement in mean score of mothers' knowledge, their adherence to antiepileptic drugs and seizure severity occurred among their children after three and six month of intervention than before. Recommendation: Educational efforts and reinforcement must be continuous to meet the needs of the mothers and their children during various stages of the disease.
\end{abstract}

Keywords: Adherence, Antiepileptic drugs, Maternal knowledge, Seizure severity, Children, Educational sessions

\section{Introduction}

Epilepsy is a group of chronic brain conditions associated with abnormal electrical disturbance in one or more areas of the brain, which characterized by recurrent epileptic seizures originating in the brain (Hockenberry \& Wilson, 2013). Epilepsy is the second common disease among chronic nervous diseases which affects approximately over 50 million patients worldwide (de Boer et al., 2008), with a prevalence rate ranging from 16 to 51 per 100,000 population in the developed countries and 35-111 per 100,000 population in the developing countries (Banerjee, Filippi and Allen-Hauser, 2009).

Antiepileptic drugs (AED) are known to be the major treatment for most of the affected children depending on several diagnostic factors such as the type of epilepsy, the frequency and severity of the seizures, as well as age and other health conditions (CDC, 2014).Issues that commonly hamper the success of drug therapy include drug resistance, poor adherence, drug-drug interactions and cost of medication (Kwan, Schachter and Brodie, 2011). In developing countries, the prevalence of poor adherence to AED therapy has been reported in up to $80 \%$ of epileptic children (WHO, 2003).

Adherence is generally defined as the extent to which patients' treatment-related behaviors such as taking medication, following a diet, modifying habits, or attending clinics that correspond to health professionals' advice (Gabr and Shams, 2015). For pediatric patients with epilepsy adherence to medication is crucial in preventing or minimizing seizures and their cumulative impact on everyday life.Medication adherence can be sufficiently defined as the taking of prescribed medication at the correct times, in the correct dosage, remembering to take doses, and continuing to take the medication for the duration prescribed (Malik, Shabbir , Saeed and Malik, 2014 ). In epilepsy non-adherence leads to lack of control over seizures, recurrence, increased absenteeism from school, possibly injury to oneself and consequently poor quality of life (Shams and Barakat, 2010). 
Non-adherence to medication is widespread and considers one of the common problems that were addressed by physicians since many pediatric patients do not follow their physicians' plan. This problem may lead to many implications concerning medicine use especially among children (Qoul et al., 2015). Several researchers indicated that (30\%-70\%) of parents have children with chronic illnesses including epilepsy had poor adherence because of extended treatment duration, multiple medications, and periods of symptomatic remission. The effects of non-adherence among epileptic children can be serious that manifested in increased morbidity and mortality of the disease, reduced cost-effectiveness of medical care from unused medications, increased clinic and emergency room visits and hospital stays ( Carbone et al., 2013).

The medication management of pediatric patients with epilepsy largely depends on the knowledge and attitudes of their parents particularly caregivers. Prior evidence showed that parents have inadequate knowledge regarding disease and pharmacotherapy of their children with epilepsy. Lack of knowledge and inappropriate beliefs are the major obstacles to successful epilepsy management (Shaju, Vinayan and Abraham 2014). Quality of life will be significantly affected by non adherence to AEDs due to the occurrence of frequent breakthrough seizures that increased hospital admissions. It may also lead to serious consequences like status epilepticus and sudden unexpected death (Monir, El-Alameey and Eltahlawy, 2013).

Education is the cornerstone to encourage a healthy attitude toward the disease and drug adherence through continuous communication between health professionals and parents of children with epilepsy regarding nature of disease, its characteristics, medications used, benefits of AEDs, dosage adjustments, potential drug interactions, adverse effects and needs for adherence to therapy is essential (Frank-Briggs and Alikor, 2011). Epileptic children adherence to medication regimens is important in the management of epilepsy. Failure to follow prescribed drug regimes will reduce the benefit that could be gained from the medication leading to uncontrolled epilepsy (Faught, et al., 2009). The mothers should plan the administration of the medications at convenient times to avoid disruptions of family routines, should understand the danger of skipping doses or omit them even if their children are free of seizures most of the time. Mothers should be aware that if their children have an illness, they are at increased risk of seizures and should contact their health professional if their children miss medications during the illness. The mothers' knowledge of potential sideeffects of AEDs is important and must be encouraged to report their observations to their health-care provider (Mbuba, 2011).

\section{Justification of the problem:}

The promotion of medication adherence is considered as an integral component of nursing care practice and good healthcare. Poor adherence to antiepileptic drug (AED) therapy can lead to various undesirable complications. An approach which focuses on the control of seizure attack and reduce its severity will have limited success without medication adherence. This study aims to examine the impact of educational Sessions on maternal knowledge, adherence to antiepileptic drugs and seizure severity among their epileptic children.

\section{Research Hypothesis:}

- Maternal Knowledge and adherence to antiepileptic drugs will be better after the educational intervention.

- The severity of epilepsy among children will be decreased after the educational intervention

\section{Subjects and method:}

Design: A quasi experimental design (pre, post three month and follow up after six month) was used in this study

Setting: study was conducted at inpatient unit and outpatient clinic of neurology department at Mansoura University Children's hospital.

Subject: Convenience samples of 100 mothers having children suffer from epilepsy who were willing to participate in the study and fulfill the inclusion criteria:

(1) children diagnosis of epilepsy and initiation of antiepileptic drug therapy with at least one drug for 12 weeks .

(2) children from 2 to 14 years of age.

(3) absence of developmental disorders and chronic illnesses requiring daily medication .

\section{Tools of data collection:}

Three tools were used to collect the required data:

I - Structured interview questionnaire: developed by the researcher after reviewing the related literatures, it composed of the following parts:

A- Basic data of the mother and their epileptic children which includes: mothers' age, level of education, occupation, residence and family history of epilepsy. Also, data about children age, sex, epilepsy disease duration, its types and types of AED were included. 
B- Mother Knowledge about antiepileptic drug: 20 questions prepared by the researchers after reviewing the related literature. It include questions about disease definition, causes, symptoms, predisposing factors of seizures, different treatment options for epilepsy, types of drug given, proper use and storage of medications, beliefs about medication efficacy and its side effects .Need for adherence to AED therapy, barriers that make it difficult for their child to take medications as prescribed and measures to sustain adherence. For each correct answer was given (1) and (0) for wrong answer, the total score was (20) the level of mothers knowledge were categorized into: Score $\geq 75 \%$ considered good, score from $50-<75$ considered as faire and score $<50$ considered as poor.

2-Medication Adherence Scale: A validated modified Morisky Adherence Scale adopted from (AlQazaz et al., 2010). It was 8 questions evaluating the mother's forgetfulness, mother understanding of the need for continued therapy and whether the mother felt it was inconvenient adhering to a daily medication treatment plan. For questions from 1- 7 categorized as yes(1) or no (0) while for 8 question, a score of one was given for 'Never/Rarely' whereas a score of zero was given for 'Once in a while' / 'Sometimes' / 'Usually' / 'All the time. Mother who had a score of (0-2) was considered as adherent. While mother who had a score of (3-8) was considered as non adherent.

3- Seizure severity scale developed by Hans et al 1996, to assess seizures frequency, duration, level of consciousness, associated signs and symptoms and complains after the attacks, The 13 items represent the following area of content : consciousness (4 items), motor symptoms ( 2 items),incontinence( 1 items), injuries $\backslash$ pain (3 items) and overall seizure severity(3 items). The scoring system was done concerning the above items. Each question response was either always, 3grades), usually, 2grades), sometimes 1 grade), or never, zero grade). The total score was 39 . The seizure severity was categorized as

Zero $=$ no seizure $\quad 1-13$ grades $=$ mild seizure

14-26 grades $=$ moderate seizure $27-39$ grades $=$ severe seizure

\section{Methods}

Permission to conduct the study was obtained from the authorized persons of El-Mansoura University children's hospital to conduct the study.The researcher introduced herself to mothers who met the inclusion criteria; each potential mothers was fully informed with the purpose and nature of the study, and then an informed verbal consent was obtained from participants who accepted to participate in the study with emphasizing that participation in the study is entirely voluntary and their withdrawal from the study would not affect the care provided, and confidentiality was assured through coding the data. The tools were tested for its content validity by five experts in the field of nursing, according to expert's suggestions the tool was modified. Reliability of tool (I- B) was tested using Cronbach's $\alpha$ (alpha). The reliability value of the tool was 0.90 that found to be highly reliable. A pilot study was carried out on $10 \%$ of the subjects (10) mothers having epileptic children for testing feasibility and applicability of the tools. Minimal modifications were made in the tools. Mothers included in the pilot study were excluded from the study subjects.

\section{Development of Educational Sessions:}

The educational Sessions on adherence to antiepileptic drugs was prepared based on the review of literature and needs of the subjects. The developed content was given to three experts to establish the content validity. According to expert's suggestions the educational sessions contents was modified.The mothers of epileptic children were interviewed by the researcher to obtain basic data and their knowledge about antiepileptic drug, adherence to medication and severity of seizure attack of their children (pre test format) within 30-40 minutes. Content of the educational sessions was given to the epileptic children mothers over one week through 4 sessions each session lasted from 30 - 45 minutes. The first session about general information for epilepsy, the second concerned with knowledge about anti epileptic drugs, the third session about seizure attack severity and the fourth session about adherence to antiepileptic drug and measures to improve adherence. The teaching methods used were lectures, discussions, pictures and booklet. After three months the studied mothers were reassessed (post test) using the same pre format and follow up was made after six months to examine the current research hypothesis.

\section{Statistical analysis:}

Collected data were computed and statistically analyzed using SPSS (statistical package of social sciences) version 16. Data were presented in tables and graphs as frequencies and percentages. Comparison of categorical variables was done using Chi square test $\left(\chi^{2}\right)$ and for continuous quantitative variables using student $t$ test. Correlation of the scores was tested using Pearson's correlation. The difference was considered significant at $\mathrm{P} \leq 0.05$. 


\section{Results}

Table (1): The characteristics of the studied mothers and their epileptic children

\begin{tabular}{|c|c|c|c|}
\hline Characteristics & Items & No & $\%$ \\
\hline \multicolumn{4}{|l|}{ *** Mother's Characteristics } \\
\hline \multirow[t]{3}{*}{ Age of mothers (years) } & $20-$ & 49 & 49.0 \\
\hline & $35-$ & 43 & 43.0 \\
\hline & $50+$ & 8 & 8.0 \\
\hline \multicolumn{2}{|l|}{ Mean \pm SD } & \multicolumn{2}{|c|}{$35.74 \pm 8.12$} \\
\hline \multirow[t]{2}{*}{ Residence } & Rural & 73 & 73.0 \\
\hline & Urban & 27 & 27.0 \\
\hline \multirow[t]{3}{*}{ Social status } & Married & 72 & 72.0 \\
\hline & Widow & 21 & 21.0 \\
\hline & Divorced & 7 & 7.0 \\
\hline \multirow[t]{5}{*}{ Education } & Illiterate & 16 & 16.0 \\
\hline & Read \& write & 44 & 44.0 \\
\hline & Secondary & 16 & 16.0 \\
\hline & University & 23 & 23.0 \\
\hline & Post university & 1 & 1.0 \\
\hline \multirow[t]{2}{*}{ Occupation } & Working & 14 & 14.0 \\
\hline & Not working & 86 & 86.0 \\
\hline \multirow[t]{2}{*}{ Family history } & Yes & 19 & 19.0 \\
\hline & No & 81 & 81.0 \\
\hline \multicolumn{4}{|l|}{ *** Child's Characteristics } \\
\hline \multirow[t]{3}{*}{ Child age (years) } & $1-$ & 38 & 38.0 \\
\hline & $5-$ & 50 & 50.0 \\
\hline & $10-15$ & 12 & 12.0 \\
\hline \multicolumn{2}{|l|}{ Mean \pm SD } & \multicolumn{2}{|c|}{$5.56 \pm 3.36$} \\
\hline \multirow[t]{2}{*}{ Gender } & Males & 59 & 59.0 \\
\hline & Females & 41 & 41.0 \\
\hline \multirow[t]{4}{*}{ Duration of illness (months) } & $12-$ & 65 & 65.0 \\
\hline & $60-$ & 30 & 30.0 \\
\hline & $120-156$ & 5 & 5.0 \\
\hline & Mean \pm SD & 46.40 & \pm 29.98 \\
\hline \multirow[t]{3}{*}{ Type of epilepsy } & General & 44 & 44.0 \\
\hline & Local / Focal & 21 & 21.0 \\
\hline & $\begin{array}{l}\text { More than one } \\
\text { type }\end{array}$ & 35 & 35.0 \\
\hline \multirow[t]{2}{*}{ Types of antiepileptic drugs used } & Mono & 46 & 46.0 \\
\hline & Multiple & 54 & 54.0 \\
\hline
\end{tabular}

It is clear from table (1) that the ages of about half (49.0\%) of studied mothers were between 20 to less than 35 years and only $8.0 \%$ of them their age were 50 years and more with the mean age of $35.74 \pm 8.12$ years. Also two third of mothers $73 \%$ were from rural areas and $72 \%$ of them were married at time of the study. As regard mother's education nearly half of them (44\%) were read and write, $23 \%$ had university graduation and $16 \%$ of them were illiterate and have secondary school. Also the majority $(86.0 \%)$ of studied mothers was not working and $81 \%$ of them have no family history of the disease. Concerning children's characteristics half of them $50 \%$ their age were from 5 to less than 10 years and $38 \%$ of them were from one to less than five years with the mean age of $5.56 \pm 3.36$ years. As regard disease duration about two third of them have from 12 to less than 60 months with the mean duration of $46.40 \pm 29.98$ months. Forty four percent of children have general types of epilepsy, $35 \%$ have more than one type and only $21 \%$ of them have local / focal types of epilepsy. Also more than half $(54 \%)$ of children used multiple types of antiepileptic drugs.

Table (2): Maternal knowledge, their adherence to antiepileptic drug and severity of epilepsy among their children before intervention

\begin{tabular}{|l|l|l|l|}
\hline Items & Categories & No & $\%$ \\
\hline Maternal knowledge & Good & 3 & 3.0 \\
& Fair & 38 & 38.0 \\
& Poor & 59 & 59.0 \\
\hline Mean \pm SD of knowledge score & Adherent & $8.40 \pm 3.54$ & 27.0 \\
\hline Adherence level & Not adherent & 73 & 73.0 \\
\hline Mean \pm SD of adherent score & Mild & $3.08 \pm 1.81$ & \\
\hline Severity of epilepsy & Moderate & 13 & 73.0 \\
& 72 & 15.0 \\
\hline Mean \pm SD of severity score & Severe & 15 & \\
\hline
\end{tabular}


The above table (2) shows that more than half of the studied mothers (59\%) have poor knowledge and only $(3 \%)$ of them have good knowledge with a mean score of $8.40 \pm 3.54$ marks before intervention. As regard adherence to antiepileptic drugs about three quarters of mothers (73\%) are non-adherent with a mean adherence score $3.08 \pm 1.81$. Also seventy two (72\%) of children has moderate severity of epilepsy, (15\%) has sever level and only $(13 \%)$ has mild level of epilepsy severity before intervention with a mean severity score of $18.69 \pm$ 5.29 .

Figure (1): Causes of non adherence of mothers to antiepileptic drugs.

This figure shows that the majority of studied mothers $(91.8 \%)$ reported that forgetness is the major causes of non- adherence to antiepileptic drug administration, then complicated system of drug therapy $(45.2 \%)$, then drug expenses (37\%) and difficulty swallowing of drugs in (35.6\%) of cases respectively.

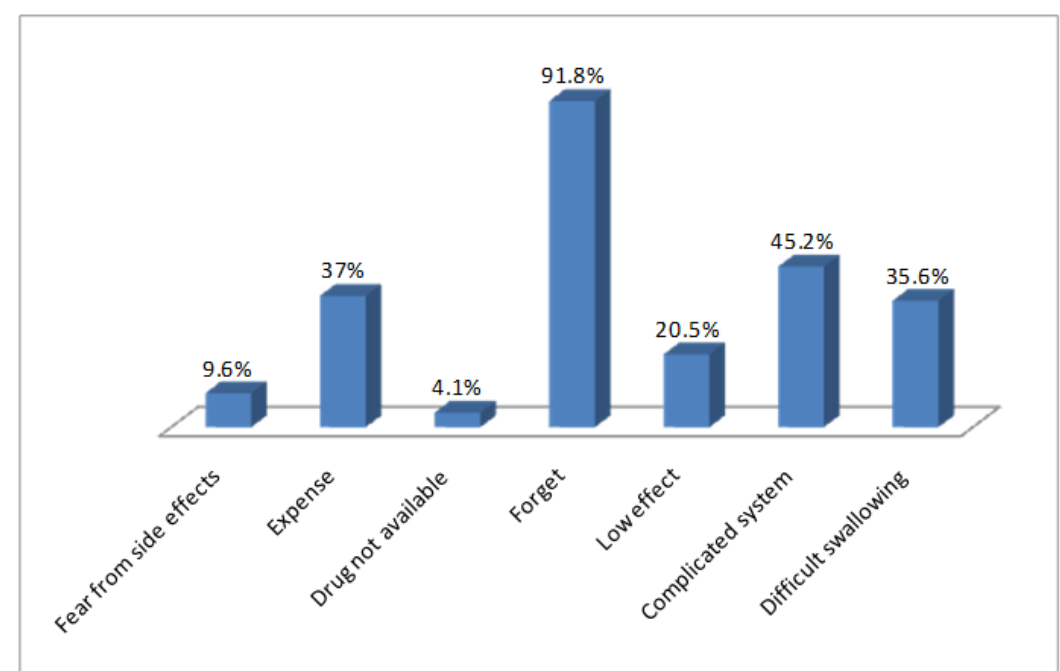

Figure (2) Comparison of knowledge level of studied mothers before and after three and six month of intervention:

This figure shows an improvement in mothers knowledge about antiepileptic drug adherence after three month of intervention than before in the form of $57 \%$ good, $33 \%$ fair and only $10 \%$ poor knowledge. After six month of intervention the mother's level of knowledge become $44 \%$ good, $38 \%$ fair and $18 \%$ poor knowledge.

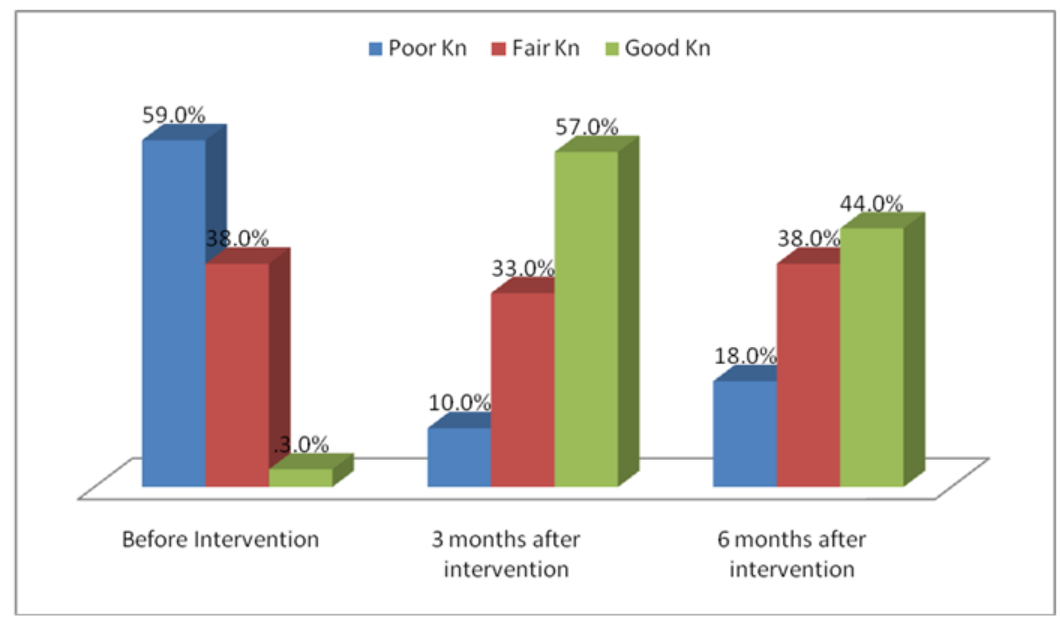

Figure (3): Comparison of adherence level to antiepileptic drugs before and after intervention.

It is clear from this figure that the majority of studied mothers $(95 \%)$ become adherent to antiepileptic drugs after three month of intervention than before and this adherence rate continuo to increase to $98 \%$ after six month of intervention. 


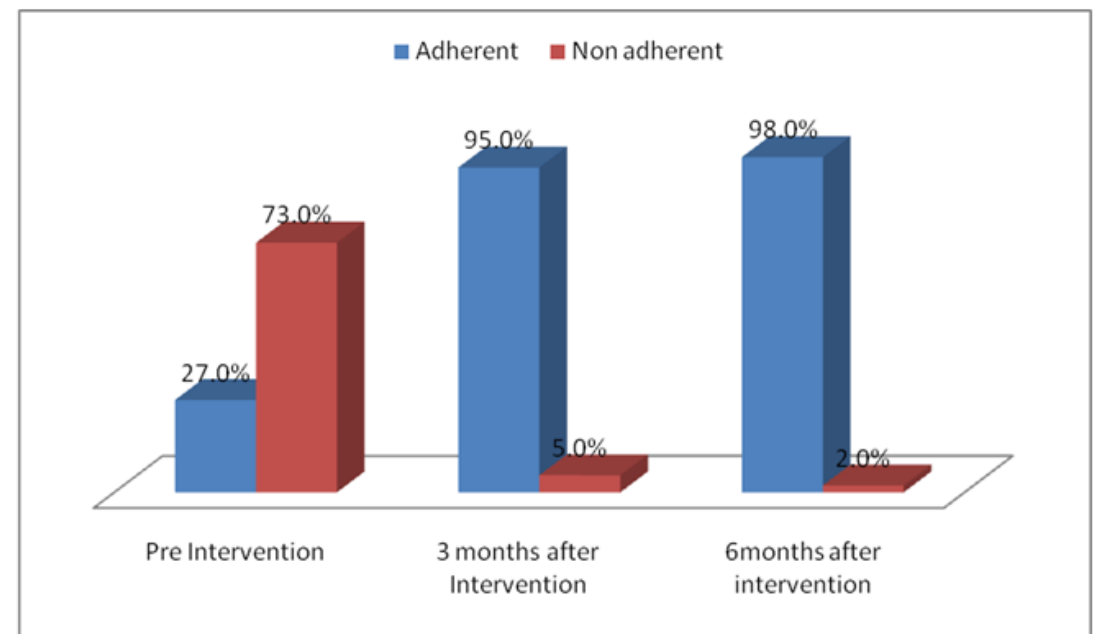

Figure (4): Comparison of the severity of epilepsy among children before and after intervention.

This figure presents level of seizure severity among epileptic children of studied mothers that shows an improvement in seizure severity level after three month of intervention in the form of $63 \%$ mild, $36 \%$ moderate and none sever compared to before intervention. While after six month of intervention only $2 \%$ of epileptic children had sever epileptic attack, $27 \%$ moderate and $71 \%$ mild level of severity.

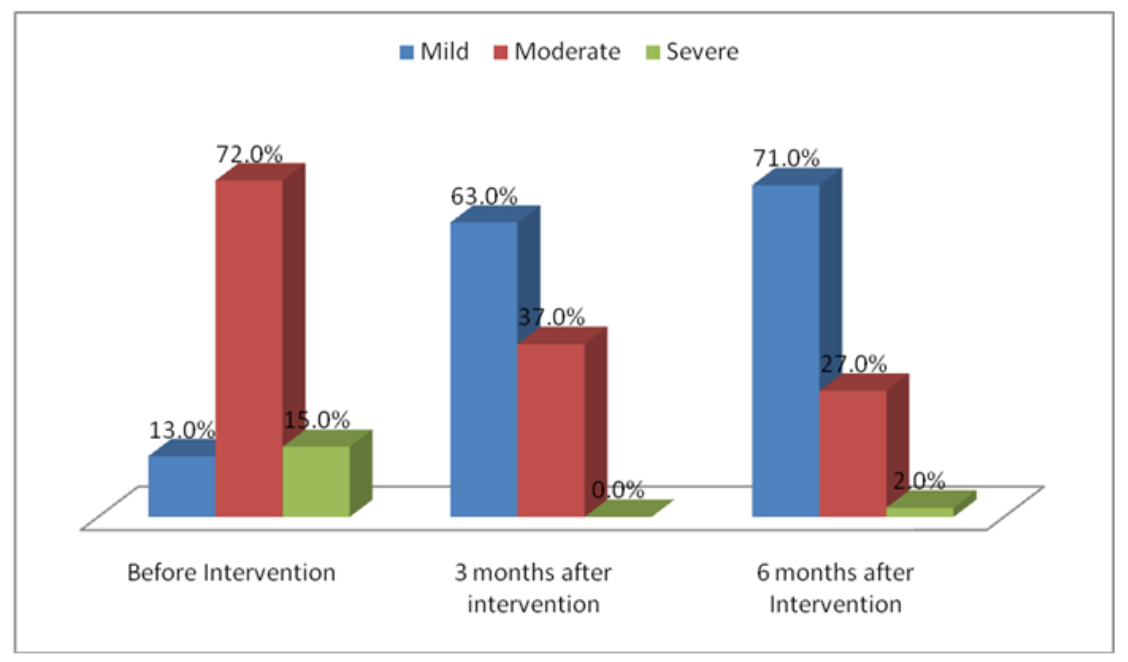

Table (3): Changes in the average scores of mothers' knowledge, their adherence to antiepileptic drugs and severity of children epilepsy after intervention

\begin{tabular}{|c|c|c|c|}
\hline & Pre-Intervention & After 3 months & After 6 months \\
\hline \multicolumn{4}{|l|}{ Knowledge score } \\
\hline $\begin{array}{l}\text { Range } \\
\text { Mean } \pm \text { SD }\end{array}$ & $\begin{array}{l}3.0-16.0 \\
8.04 \pm 3.54\end{array}$ & $\begin{array}{l}7.0-20.0 \\
14.39 \pm 3.91\end{array}$ & $\begin{array}{l}7.0-19.0 \\
13.33 \pm 3.46\end{array}$ \\
\hline Significance test & $\begin{array}{l}\text { Pre Vs } 3 \text { month } \\
\mathrm{t}=29.543, \mathrm{P} 0.000\end{array}$ & $\begin{array}{l}\text { Pre Vs } 6 \text { month } \\
\mathrm{t}=24.823, \mathrm{P} 0.000\end{array}$ & $\begin{array}{l}3 \text { mon Vs } 6 \text { mon } \\
t=4.515, P 0.000\end{array}$ \\
\hline \multicolumn{4}{|l|}{ Adherent score } \\
\hline $\begin{array}{l}\text { Range } \\
\text { Mean } \pm \text { SD }\end{array}$ & $\begin{array}{l}0.0-6.0 \\
3.08 \pm 1.81\end{array}$ & $\begin{array}{l}0.0-3.0 \\
1.29 \pm 0.95\end{array}$ & $\begin{array}{l}0.0-3.0 \\
1.06 \pm 0.86\end{array}$ \\
\hline Significance test & $\begin{array}{l}\text { Pre Vs } 3 \text { month } \\
\mathrm{t}=14.418, \mathrm{P} 0.000\end{array}$ & $\begin{array}{l}\text { Pre Vs } 6 \text { month } \\
\mathrm{t}=12.099, \mathrm{P} 0.000\end{array}$ & $\begin{array}{l}3 \text { mon Vs } 6 \text { mon } \\
t=2.781, P 0.006\end{array}$ \\
\hline \multicolumn{4}{|l|}{ Severity score } \\
\hline $\begin{array}{l}\text { Range } \\
\text { Mean } \pm \text { SD }\end{array}$ & $\begin{array}{l}10.0-31 \\
18.04 \pm 5.29\end{array}$ & $\begin{array}{l}8.0-26.0 \\
14.79 \pm 4.38\end{array}$ & $\begin{array}{l}10.0-27.0 \\
14.09 \pm 4.47\end{array}$ \\
\hline Significance test & $\begin{array}{l}\text { Pre Vs } 3 \text { month } \\
\mathrm{t}=17.880, \mathrm{P} 0.000\end{array}$ & $\begin{array}{l}\text { Pre Vs } 6 \text { month } \\
\mathrm{t}=14.445, \mathrm{P} 0.000\end{array}$ & $\begin{array}{l}3 \text { mon Vs } 6 \text { mon } \\
t=2.890, P 0.005\end{array}$ \\
\hline
\end{tabular}

Table (3) shows significant improvement in mean score of mothers' knowledge, their adherence to antiepileptic drugs and seizure severity occurred among their children after three and six month of intervention. With statistical significant difference between mean score of knowledge, adherence and severity of seizure before and after three month, before and after six month and between three and six month of intervention . 
Table (4): Correlation between maternal adherence to antiepileptic drugs and their knowledge and severity of epilepsy among their children before and after intervention

\begin{tabular}{|c|c|c|c|c|c|c|}
\hline \multirow{3}{*}{ Items } & \multicolumn{6}{|c|}{ Adherence } \\
\hline & \multicolumn{2}{|c|}{ Before Intervention } & \multicolumn{2}{|c|}{3 months after Intervention } & \multicolumn{2}{|c|}{6 months after Intervention } \\
\hline & $\mathrm{r}$ & $\mathrm{p}$ & $\mathrm{r}$ & $\mathrm{p}$ & $\mathrm{r}$ & $\mathrm{p}$ \\
\hline $\begin{array}{l}\text { Maternal } \\
\text { knowledge }\end{array}$ & 0.168 & 0.095 & 0.316 & 0.001 & 0.301 & 0.001 \\
\hline $\begin{array}{l}\text { Severity of } \\
\text { epilepsy }\end{array}$ & -0.196 & 0.051 & -0.229 & 0.002 & -0.406 & 0.000 \\
\hline
\end{tabular}

Table (4): shows correlation between maternal adherence to antiepileptic drugs and their knowledge and severity of epilepsy among their children. There was no statistical significant correlation between mothers ' adherence score to antiepileptic drugs and maternal knowledge before intervention $(r=0.168, p 0.095)$ and after three and six months of intervention, there was significant positive moderate correlation $\mathrm{r}=0.316, \mathrm{p}=0.001$ and $\mathrm{r}=0.301, \mathrm{p}=0.001$, respectively. Also, there was no statistical significant correlation between mothers ' adherence score to antiepileptic drugs and seizure severity before intervention $(r=-0.196, p 0.051)$. And there was statistical significant negative mild and moderate correlation between mothers ' adherence score to antiepileptic drugs and seizure severity scores after 3 months and 6 months of intervention where $(r=-0.229$, $\mathrm{P}=0.002$, and $\mathrm{r}=-0.406 \mathrm{P}=0.000$, respectively).

\section{Discussion}

Adherence to the prescribed antiepileptic medication plan is crucial in pediatric patient with epilepsy to control seizure, which in turn compromises the quality of life (Gabr and Shams 2015). The present study clarifies that more than half of the studied mothers have poor knowledge and the minority of them have good knowledge about the disease and antiepileptic drugs before intervention regardless of their age, education or duration of their children illness (table 2). This finding may be attributed to the scientific terminology connected to epilepsy and antiepileptic drugs used. In addition, mothers' get used to the illness because of the chronic nature of the disorder so they do not ask or search about their children's illness. They were concerned about the seizures and their effect on various aspects of the lives of children, as well as long term side effects of AEDs. Also, this finding may reflect the insignificant role played by nurses as health educators or counselors in stressing the importance of adherence to the drug regimen, proper use, storage, potential side effects and interactions of drugs. This finding is congruent with Badawy (2015) who found poor maternal total knowledge score about epilepsy. But after three and six month of intervention there was an improvement in mothers' knowledge than before (figure 2 \& table 4). Shaju, Vinayan and Abraham (2014) found on their study a gap of knowledge concerned with medications and therapy of epilepsy. Although, the parents of children with epilepsy were knowledgeable regarding the nature of epilepsy, its characteristics, causes, and prognosis, they were less aware about the nature of treatment, its objectives, use of drugs, adherence to the drug regimen, and duration of treatment. Also, many parents were worried about the effects of long term administration of drugs and the chance of drug dependence.

Another study by Shah et al., (2011) demonstrated lack of mothers' awareness about the proper usage of drugs, storage of medicine and their expiry dates. Also, a study made by Behrouzian and Neamatpour, (2010) indicated that mothers' information needs are not being met and indicated that their need for information remained high, so they continue to have questions about anti-epilepsy drugs and wanting more information about how to keep their children safe during a seizure. Although the results of the present study shows poor knowledge of mothers about epilepsy, AEDs and adherence regimen before intervention , this results contradicted with (Frank-Briggs and Alikor, 2011) who stated that parents of children with epilepsy of 8 to 17 years of age who knew about epilepsy were found to be more aware about antiepileptic drugs used and their side effects.

Adherence to medication is regarded as a major challenge in developing countries as a result of illiteracy, ignorance, and low income (Mbuba, 2011). The present study indicated that about three quarters of mothers were non-adherent to AEDs administration before intervention (table 2). This may because of their poor level of knowledge about their children medication in addition to their negative attitude towards their children diseases that connected with social stigma. But after three months of implementing educational sessions the majority of mothers become adherent to antiepileptic drug administration and the percentage increased after six month of intervention with statistical significant difference between before and after intervention $(\mathrm{p}<0.05)$ (figure3 \& table 3). This improvement may results from the effect of educational Sessions in stressing the importance of adherence to the antiepileptic drug regimen and changing the negative attitude towards prescribed medication. These results come in agreement with Gabr and Shams (2015) who reported that The prevalence of self-reported poor adherence to AED therapy among the study subjects is higher. 
The present study illustrated that, the common causes of non-adherence to antiepileptic drug regimen before intervention from mothers ware forgetness then complicated system of treatment (figure 1). This results agreed with several studies as Qoul et al., (2015) who investigated the top reasons for non-adherence to AED medications was Parents' forgetfulness to give medications to their children in $52.2 \%$ of cases . Nakanwagi, (2015), who also found that forgetfulness was the primary cause of non adherent by $69.6 \%$ of mothers. And Wael et al., (2015) who found that forgetfulness is the most common cause of non-adherence among a group of adolescent patients. As well as, Tang et al., (2013) indicated that forgetfulness by $54.2 \%$ is the main reason for non-adherence. While the results of the present study contradicted with Shaju, Vinayan and Abraham (2014) who stated that The primary reason for non adherence $(85.36 \%)$ was fear of side effects, $(27.64 \%)$ of parents found it difficult due to polypharmacy, other reasons reported were increased frequency of dosing in $(18.6 \%)$, cost of medications in $(17.89 \%)$ and prolonged duration of therapy in $(13.82 \%)$ of parents and only $(8.13 \%) \&(9.76 \%)$ of them ranked patient related factors like forgetfulness and travel respectively as other reasons for non adherence to antiepileptic drug therapy.

Regarding seizure severity score about three quarter of studied children has moderate severity of epilepsy and the minority of them had mild level of severity before intervention (table 2). This may due to most of mothers were non adherent to antiepileptic drug administration. But after the intervention there was statistical significant improvement after three month and continued after 6 months of intervention compared by before (figure 4\&table 3). The improvement may be due to increasing mothers' knowledge about the disease and antiepileptic drugs as most of epileptic children mothers are not well informed, have significant misconceptions and negative attitudes towards antiepileptic medication. In addition, increased their adherence to antiepileptic medication which in turn affects on seizure control and severity, also mothers realized the benefits of adherence as time passed because they learn from the intervention given and their personal experience. These findings were in agreement with Modi et al., (2008) who mentioned that compliance to prescribed medication plan lead to good seizure control and vice versa.

Concerning correlation between maternal adherence to antiepileptic drugs and their knowledge and severity of seizure among their children ,the results of the present study revealed that there was no correlation between maternal adherence to antiepileptic drugs and their knowledge before intervention, but after three and six months of intervention a positive significant correlation was founded (table 4). This may because educational intervention removes false believes associated with social stigmatization from the disease. They got more information about treatment regimen and facilities, as well as the importance of correct adherence to treatment plan. These findings were in agreement with Shaju,Vinayan and Abraham (2014) who illustrated that improving the understanding about epilepsy and its management along with the overall medical care may ultimately enhance adherence, which will help to improve the therapeutic outcomes and overall quality of life in children with epilepsy. However medication adherence in epilepsy is mainly related to the knowledge regarding the importance of regular drug intake.

Also, the present results clarified negative significant correlation between maternal adherence to antiepileptic drugs and seizure severity scores after three and six month of intervention (Table 4). This may due to mothers' effort to adhere and give drugs on time to their children. Nearly similar findings were obtained from the study of Solomon and McHale (2012) \& Farahat et al., (2010) who reported a low frequency of daily fits with drug compliance on their study sample. The current finding contradicted with Mansy et al(2012) who found statistical significant positive correlation between seizure severity score and quality of life immediately and 3 months after educational program due to the unpredictability of seizure, the probable associated events like incontinence, injury or even suffocation and death.

\section{Conclusion}

An improvement in mean score of mothers' knowledge, their adherence to antiepileptic drugs and decrease in seizure severity scores among their epileptic children after three and six month of educational intervention than before.

\section{Recommendation}

- Educational efforts and reinforcement must be continuous to meet the needs of the mothers and their children during various stages of the disease.

- Assessment of medication adherence among epileptic patients should be a routine part of the management process.

Acknowledgment

The researchers' offers greatest thanks and appreciation to all mothers participated in the study. 


\section{Reference}

[1]. Al-Qazaz HK, Hassali MA, Shafie AA, Sulaiman SA, Sundram S, Morisky DE. (2010): The eight-item morisky medication adherence scale MMAS: translation and validation of the malaysian version. Diabetes Res Clin Pract ; 90:216-21.

[2]. Badawy G. GH. (2015): Maternal knowledge and management of their children with epilepsy. Unpublished Thesis of Master Degree in Pediatric Nursing, Mansoura University.

[3]. Banerjee, P.N., Filippi, D., Allen-Hauser, W., (2009). The descriptive epidemiology of epilepsy-a review. Epilepsy Res. 85 (1), $31-$ 45.

[4]. Behrouzian, F. and Neamatpour, S. (2010): Parental knowledge and mental health in parents of children with epilepsy. Pak Journal Medical Science; Vol 26. No (1): Pages 191-194

[5]. Carbone L, Zebrak B, Plegue M, Joshi S and Shellhaas R. (2013) Treatment adherence among adolescents with epilepsy: what really matters? Epilepsy Behav; 27(1): 59-63.

[6]. Center of disease control and prevention (CDC) (2014). CDC - Epilepsy - Basics - FAQs. Available at http:// www. cdc.gov/ epilepsy/basics/faqs.htm [Accessed October 23, 2014].

[7]. de Boer, H.M., Mula, M., Sander, J.W., (2008). The global burden and stigma of epilepsy. Epilepsy Behav. 12 (4), 540-546.

[8]. Farahat, T.M., El-Shafie, A.M. and Abd-El-Rasoul, G.M., et al. (2010): Integrated Management of Epilepsy among Basic School Children in Menoufiya Governorate. Egypt Jounal Neurol Psychiatry Neurosurgry; Vol 47 (1), Pages 49-58.

[9]. Faught F.E ,Weiner J.R and Guerin A.et al.(2009): Impact of non- adherence to antiepileptic drugs on health care utilization and costs: findings from the RANSOM study. Epilepsia ;50(3)p:501-509.

[10]. Frank-Briggs AI and Alikor EA.(2011): Knowledge and attitudes of parents toward children with epilepsy. Ann Afr Med ;10: 238242 .

[11]. Gabr, M.W and Shams E.M. (2015): Adherence to medication among outpatient adolescents with epilepsy. Saudi Pharmaceutical Journal ;23, 33-40.

[12]. Hans A, Willem F, Vermeulen J, et al. (1996): Parent completed scale for measuring seizure severity and severity of side effects of antiepileptic drugs in childhood epilepsy: development and psychometric analysis. Epilepsy Research , (24): 173-181.

[13]. Hockenberry M and Wilson D. (2013): Wong's essential of pediatric nursing, the child and cerebral dysfunction. 9 th edition; Mosby, Elsevier, USA, pp:956- 966.

[14]. Kwan P, Schachter SC, Brodie MJ. (2011): Drug-Resistant epilepsy. N Engl J Med ; 365:919-26.

[15]. Malik A.M, Shabbir N, Saeed M and Malik H. (2014): Evaluation of Factors Influencing Medication Adherence in Children with Epilepsy in Under- Resource Community at Bhakhar City of South-Punjab, Pakistan. J Ophthalmic Pathol ; 3:4.

[16]. Mansy, G., Elshehawy, A. and El-sayed, E., et al. (2012): Maternal practice and its effect on Quality of Life of their Epileptic Children, Nature and Science; 10(2).

[17]. Mbuba K.C. (2011): Epilepsy treatment gap in developing countries: a systematic review of magnitude, causes and intervention strategies. Epilepsia. ;49(9), pp: 1491-1503.

[18]. Modi AC(2008): One Month adherence in children with new onset epilepsy white coat compliance does not occur. J Pediat; $121: 1616-25$.

[19]. Monir Z.M,El-Alameey I.R and Eltahlawy E. (2013): Health related quality of life of children with epilepsy in Egypt. Journal of the arab society for medical research.p: 53-66.

[20]. Nakanwagi M (2015).Non Adherence to Antiepileptic Drugs in a Child with Epilepsy: A Case Report. Int. Inv. J. Med. Med. Sci. Vol. 2(2): 29-33

[21]. Qoul Z.K, Qasem A.D, Samawi H.O, Matter N.L, Abo-tineh I.S and Abo-olem M.An (2015): epileptic medication adherence in children with epilepsy at Queen Rania Al-Abdulah children hospital. Research and Pharmaceutical Sciences October 2015; 2(10).

[22]. Shah AP, Parmar SA, Ramkishan A, Mehta AA.(2011): Knowledge, attitude and practice (KAP) survey regarding the safe use of medicines in rural area of Gujarat. Adv Trop Med Pub Health Int.; 1:66-70.

[23]. Shaju M, Vinayan P.K and Abraham S. (2014) Knowledge, attitude and practice of parents regarding pediatric antiepileptic drug therapy .International Journal of epilepsy. P: 57-63.

[24]. Shams, M.E., Barakat, E.A., (2010): Measuring the rate of therapeutic adherence among outpatients with T2DM in Egypt. Saudi Pharm. J. 18 (4), 225-232.

[25]. Solomon, N. and McHale, K. (2012): An overview of epilepsy in children and young people; Volume 24, Number 6.

[26]. Tang F., Zhu g., Jio Z. Ma C., wang B. (2013): "self -reported adherence in pateints with epilepsy who missed their medication and reasons for nonadherence in china”, Epilepsy and Behavior, Vol27, issue 1, pp. 85-89, April 2013.

[27]. Wael M. Gabra, b, Mohamed E.E. Shamsc, (2015): "Adherence to medication among outpatient adolescents with epilepsy", Saudi Pharmaceutical Journal.Vol 23, Issue 1, Pages 33-40, January 2015.

[28]. WHO (2003): Adherence to Long-term Therapies: Evidence For Action. Geneva: World Health Organization. 2003. 